\title{
VIVIR entre lenculas Entrevista con ADAN KOVACSICS
}

\section{Mario Salvatierra}

○ urante la Xxv emisión del Encuentro Internacional de Traductores Literarios, celebrada en el año 2016, tuve la oportunidad de conocer y platicar con Adan Kovacsics, traductor de más de una treintena de títulos de literatura germana y húngara contemporánea y del siglo $\mathrm{xx}$, entre los que destacan sus versiones de la obra de Imre Kertész, László Krasznahorkai, Adam Bodor, Karl Kraus, Heimito von Doderer, Franz Kafka y Elías Canetti, entre otros tantos más.

De padres húngaros, Kovacsics nació en 1953 en Chile, donde transcurrió su niñez en un ambiente multicultural en el que convivían la lengua española, la alemana y la húngara. En 1967 se trasladó junto con su familia a Austria, donde hizo estudios en filología románica e inglesa y en filosofía en la Universidad de Viena. Luego, en 1980, consecuente con su identidad plural, se estableció en Barcelona, donde hizo sus primeros trabajos como traductor de textos técnicos y comenzó su formación como traductor literario bajo el magisterio de Juan José del Solar. Desde entonces, ha traducido para prominentes casas editoriales, como Alianza Editorial, Galaxia Gutemberg, Herder, Tusquets, Minúscula y, especial-

...Traductor de más de una treintena de títulos de literatura germana y húngara contemporánea y del siglo XX, entre los que destacan sus versiones de la obra de Imre Kertész, László Krasznahorkai, Adam Bodor, Karl Kraus, Heimito von Doderer, Franz Kafka y Elías Canetti, entre otros tantos más.

mente, El Acantilado, donde es uno de los trujamanes estelares.

Además de traductor versátil, Kovacsics es ensayista y narrador. Ha publicado una coherente y audaz obra literaria que se integra por Guerra y lenguaje (Acantilado, 2007), Karl Kraus en los últimos dias de la humanidad (Ediciones Universidad Diego Portales, 2015) y los relatos de El vuelo de Europa (Ediciones del Subsuelo, 2016). La preocupación por el lenguaje, la memoria y la identidad son una constante en estos libros que pertenecen a esa tribu de obras no convencionales que difuminan los límites entre los géneros literarios y que entremezclan ficción con autoficción, diversas técnicas del discurso literario con materiales extraliterarios.

Entablé contacto con Adan por correo electrónico y acordamos hacer la entrevista el primer día del encuentro de traductores, que se llevó a cabo en la Sala Carlos Chávez del Centro Cultural Universitario en CU. Luego de la inauguración, los asistentes se habían levantado para saludarse y platicar, llenando la sala de ruido y haciendo difícil encontrar con la mirada a quien habría de entrevistar. Me moví entre la gente, hurgando los rostros por si identificaba a Adan en alguno de ellos, pero no tuve suerte. Subí los escalones hasta los asientos superiores de la sala y desde ahí identifiqué a un hombre de ojos amables y bigote blanco que estaba sentado en los asientos de la primera fila, observando a la concurrencia como un niño que espera tranquilamente a que los adultos terminen de tratar asuntos sin importancia. $\mathrm{Me}$ acerqué a él y me presenté. Decidimos salir del auditorio para hacer la entrevista y encontramos una banca disponible sobre uno de los derroteros del centro cultural. La 


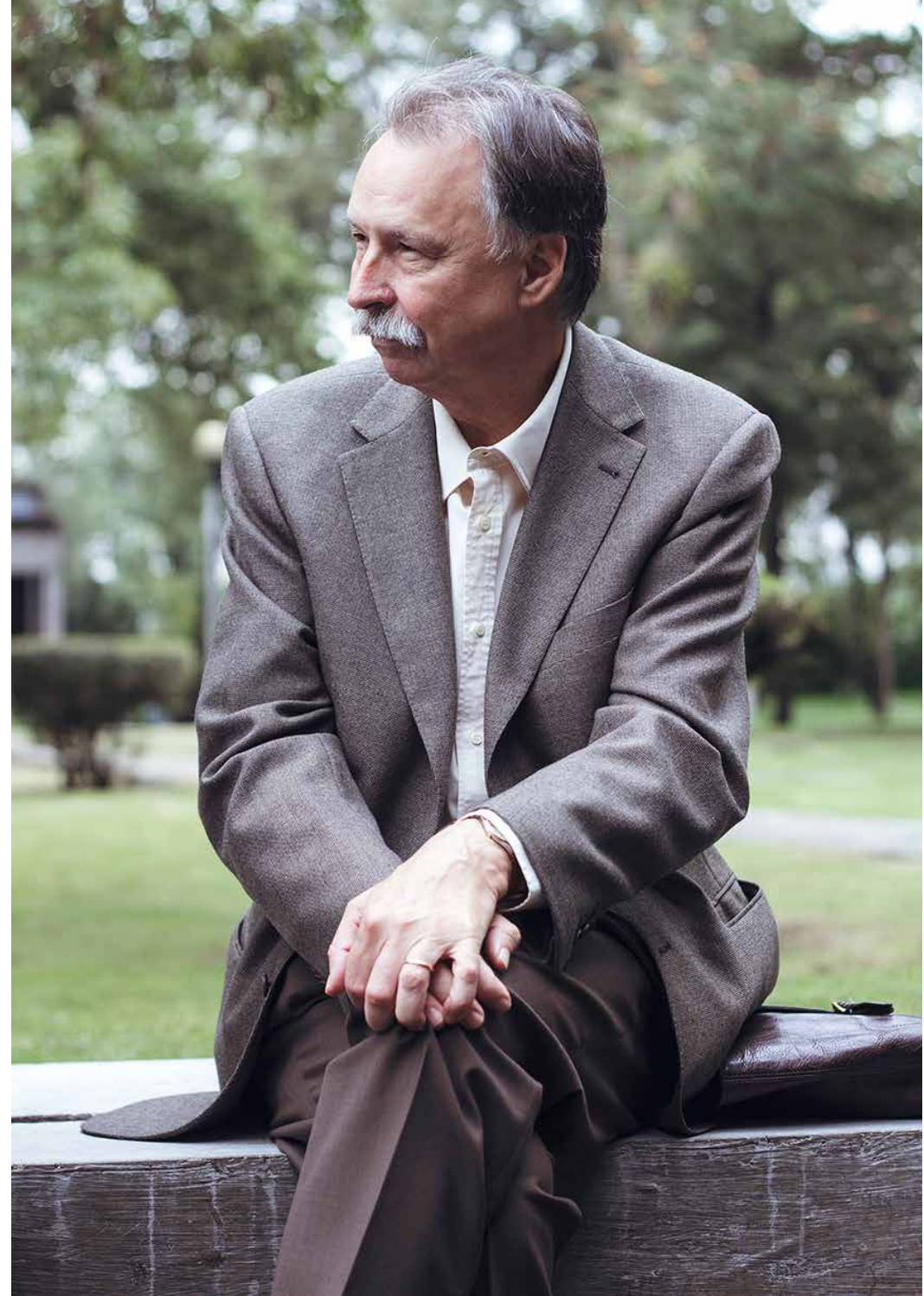

Adan Kovacsics. Foto: Sandra Florencia

noche anterior había llovido y el ambiente de la mañana era fresco y límpido. Grupos de estudiantes y visitantes del Museo Universitario de Arte Contemporáneo (MUAC) paseaban por los alrededores. La informalidad del espacio y la afabilidad de Kovacsics ofrecieron a la conversación un ritmo relajado y un carácter desprovisto de pretensiones y pedanterías.

Mario Salvatierra: Gracias por haber aceptado la entrevista.

Adan Kovacsics: Encantado, encantado.

MS: Quiero comenzar con la siguiente pregunta. Se ha dicho de ti que eres paciente, preciso y meticuloso, tres atributos importantes del traductor y del maestro; yo agregaría, del artesano. En ese sentido, ¿consideras que la labor traductora está emparentada con el trabajo artesanal, incluso con la creación artística?

AK: Totalmente. No pienso tanto en el artesano, aunque, sí, es correcta la comparación. Más que en lo artesanal, pienso en el aspecto creativo. No hay la menor duda de que hay un lado esencialmente creativo en la traducción. El que no ve la traducción como una labor creativa, creo que va por el camino equivocado de la traducción literaria. Evidentemente, no es solo crear; hay otros elementos que intervienen también que son específicos de la traducción. Esa relación entre las lenguas, ese vivir entre las lenguas, es algo muy propio de la traducción que va más allá de la creación.

MS: En una ocasión mencionaste que tu relación con la lengua y la literatura húngara era conflictiva, ya que las considerabas terreno de tu padre. Actualmente, ¿cuál es el carácter de este vínculo?, ¿ha dejado de ser conflictivo?

AK: Ha dejado de ser conflictivo. La literatura húngara era, en $\mathrm{mi}$ infancia, territorio de mi padre. No nací en Hungría, nací en Chile; después, nos trasladamos a vivir a Austria, por lo cual crecí en entornos que no eran húngaros. De tal manera que la literatura y la cultura húngaras pertenecían a mis padres. En tanto, yo tenía otros mundos, que eran más míos que de ellos: el chileno, durante la infancia, y el austriaco, el ámbito alemán, ya luego en la adolescencia y la juventud.

Allí hubo un elemento conflictivo, incluso una cierta negligencia respecto a lo que es la literatura húngara, pero que luego recuperé porque evidentemente yo iba leyendo libros húngaros, literatura húngara que conocía, precisamente, a través de mi padre, que tenía autores muy queridos. Sin embargo, luego tuve que redescubrirla por mi cuenta. Esta fue una experiencia importante. Después de la muerte de mis padres fui a Hungría, establecí relación con el país y tuve mucho interés, muchísimo, en que esa relación fuese a través de la literatura. Es decir, para mí, entrar a Hungría a través de la literatura era lo esencial. De ahí proviene la importancia, personal, existencial, de dedicarme a la traducción de la literatura húngara.

MS: Asimismo, ¿no se encuentra el traductor en un conflicto entre la lengua de la que traduce y la lengua a la que traduce? 




AK: Absolutamente. Ese vivir entre lenguas, que es el lado existencial del traductor, es una existencia llena de conflicto; para empezar, porque no existe un equilibrio. En realidad, esa sensación es la de la relación del hombre con la lengua. La sensación de que la lengua es algo a lo que nunca accederás del todo, nunca llegarás al final de la lengua, nadie llegará nunca a eso. Creo que quien ve y comprende más que nadie esta imposibilidad es el traductor y además lo ve en dos lenguas: la lengua en la que traduce y a la que traduce. Ve su insuficiencia, su incapacidad. Todo esto genera conflicto, desde luego. Por ejemplo, el mero hecho de encontrar un término que reconoces, que entiendes en la lengua de partida y que sabes que no vas a poder reproducir exactamente en la lengua de llegada genera un conflicto y es un conflicto con el que vivimos todos los días los traductores.
MS: Podríamos, también, hablar de un conflicto entre el traductor y el escritor a quien traduce, sobre todo si este está vivo. Recuerdo la anécdota que narraste sobre la traducción de El fin de una saga de Péter Nádas, obra en la que cada capítulo presenta un solo párrafo. En una primera versión, la traducción reproducía los diálogos por medio de guiones y en párrafos separados, pero después algo te dijo que esto no podía ser, que debías mantener la forma del original. Luego, confirmaste esta corazonada al hablar con el autor, quien insistió en que la traducción debía conservar los diálogos dentro de un mismo párrafo.

AK: Sí, sí. Me alegra esto. Estás recuperando historias pasadas. Me divierte. Historias bastante antiguas. Es muy curioso, es una de las cosas curiosas de una persona que traduce autores contemporáneos; la relación con estos autores es algo muy peculiar; cada uno es un mundo.

MS: Por otro lado, no todo es conflicto en la traducción literaria, pues también ofrece retribuciones y recompensas, no solo a la lengua de llegada. Pienso en lo que has mencionado sobre la traducción de literatura centroeuropea, que, al ser traducida, se enriquece. $i \mathrm{De}$ qué manera ha enriquecido el español a esta literatura?, ¿qué ha ganado el español?, iha sido un enriquecimiento bilateral?

Aк: Bueno, lo que suelo decir, y siempre insistiré en ello, es que hay un punto de pobreza en que una obra quede confinada a su lengua original. En el momento en que esa obra empieza a plasmarse en otras lenguas, se enriquece, y lo hace porque todo el acervo de esa otra lengua se introduce en la original. En una frase española está todo el español, en una frase húngara está todo el húngaro, en una 


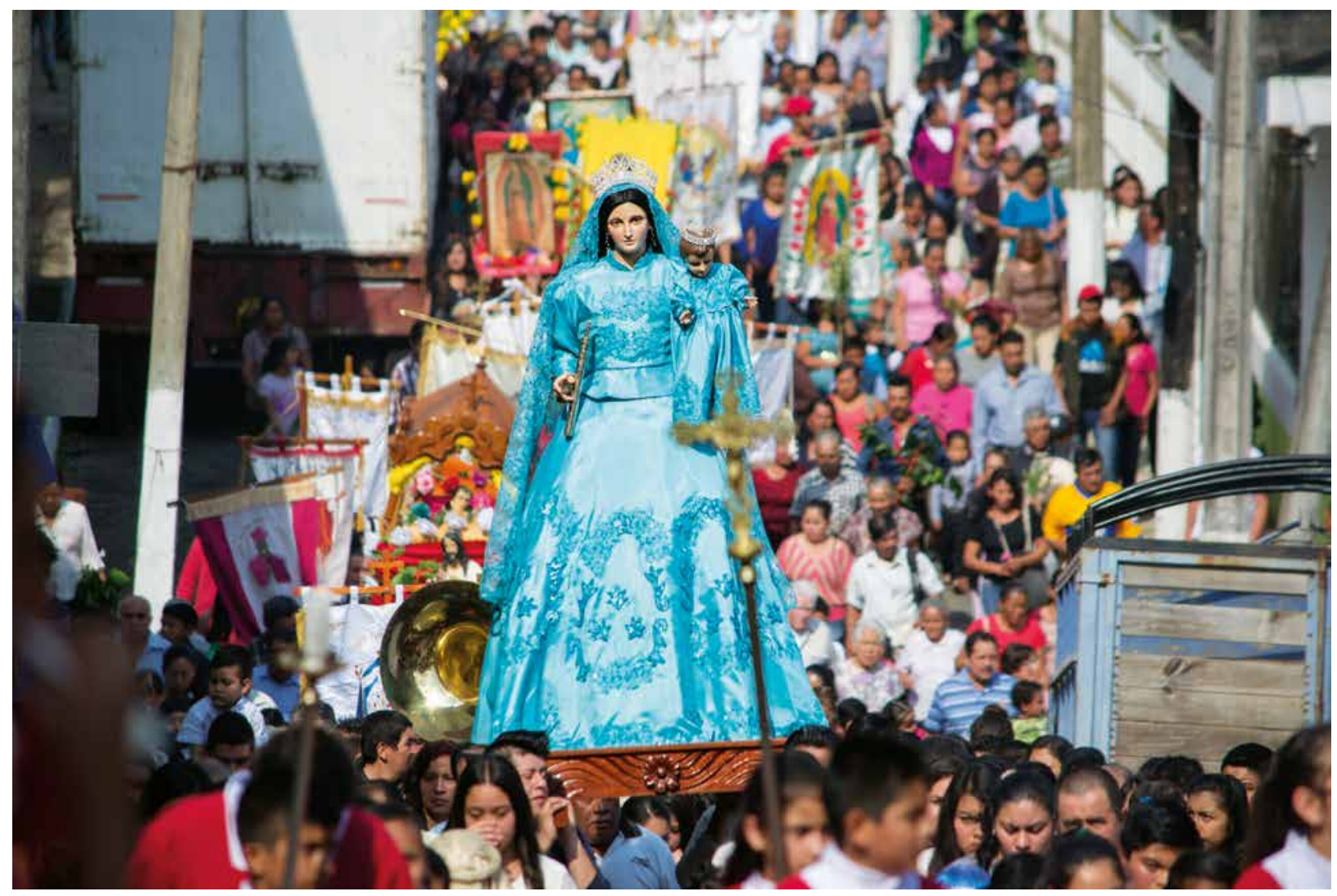

frase inglesa está todo el inglés. En el momento en que ese texto húngaro aparece en castellano se ha enriquecido con todo el castellano. Todo el castellano, de pronto, aflora en ese texto húngaro, con lo cual ha enriquecido el texto. Simplemente eso, es esa la operación. Concretamente, en qué se ha enriquecido, no lo sabría decir, pues es una ganancia tan enorme que es imposible de cuantificar. Por supuesto, todo esto sobre la base de que una traducción esté bien hecha porque hay traducciones que no enriquecen, sino que empobrecen.

MS: Gracias a tus traducciones, los lectores hispanos hemos conocido a numerosos escritores centroeuropeos. Incluso si se trata de escritores de los que nunca hemos oído hablar, basta ver que la traducción está firmada por ti para saber que hay una garantía en cuanto a la calidad del autor, la obra y la traducción. Se pensaría que tienes un olfato especial para identificar autores y obras. ¿Cómo apuestas por un escritor y su posible posteridad?

AK: Ese lado de la labor del traductor como promotor, que busca autores que puedan interesar al público español, al público en otra lengua, siempre lo reivindico mucho. El mundo literario no suele conocer lo suficiente al traductor, pero no soy el único, somos muchos los traductores que nos dedicamos cien por ciento a la traducción literaria y que conocemos la literatura de la cual traducimos. Todo eso nos permite situar a los autores, saber quién tiene valor, quién no lo tiene tanto. Saber quiénes tienen vocación universal en su obra, de manera que tendrá sentido traducirlos. En mi caso, he tenido la suerte, para empezar, de hablar esa lengua tan endemoniada que es el húngaro, de tener un cierto background literario y de poder indagar en autores y hacerlos míos.

Te doy un ejemplo. Béla Hamvas, de quien traduje La filosofía del vino para Acantilado. Ahora me encuentro haciendo una antología de textos suyos. A Hamvas se lo propuse yo a la editorial. Por otro lado, ha habido casos en que los autores han sido descubrimientos para mí, en que el editor $u$ otro traductor me han permitido esos descubrimientos. Me ha pasado con Miklós Szentkuthy, que descubrí a través de la traducción de mi colega ya fallecida Judit Xantos. Es decir, todo esto es una rueda que se va moviendo continuamente, claro.

MS: Como traductor de literatura centroeuropea, ; consideras que formas parte de alguna tradición de traductores hispanos?

AK: Soy chileno de nacimiento, pero me hice traductor en España. Tuve un maestro: Juan José del Solar. Él me inició en la traducción. 
Recuerdo las primeras páginas que traduje y que él corrigió de las cuales quedaron tres o cuatro palabras mías y el resto eran tachones negros $y$ fueron realmente años de aprendizaje con Juan. En ese sentido, sí me reconozco deudor de alguien. Sin embargo, no estoy seguro de poder hablar de una tradición. Sé que formo parte de ese grupo de traductores que surgió a finales de los setenta en España, en el que había una concepción muy rigurosa de la traducción y que quizá no existía tanto antes.

MS: A veces, imagino que el traductor se pone la máscara del autor a quien traduce. En tu caso, podríamos hablar de máscaras. Conozco, no obstante, casos de traductores que no pudieron quitarse la careta, digamos, que se les había adherido. ¿Alguna vez has sentido ese riesgo o peligro?, ¿cómo lidias con él?

AK: El peligro existe. Creo que ahí hay que tener una actitud profesional y saber mantener cierta distancia. Creo que eso es importante. Hay traductores a los que estimo mucho y, digamos, que de alguna manera se identifican con el autor, se convierten casi en su alter ego. Me parece extraordinario. Por mi parte, yo soy un traductor profesional, he traducido de todo. He traducido libros de autores con los que no me sentía particularmente identificado. Poco a poco, he podido ganar una posición como traductor que me ha permitido traducir a autores que a mí me dicen mucho: Karl Kraus o al propio Kertész. Pero no hasta el punto de llegar a una identificación. Eso sí, son autores sobre los que yo reflexiono continuamente, que están presentes en mi obra ensayística o literaria: Kertész, Kraus o Kafka. Pero no podría hablar de una identificación.

La traducción fue otra forma de relacionarme con la literatura. Eso es lo que yo quería: vivir en y para la literatura. La traducción fue una de las formas. La otra es la escritura. Tuve que hacer un proceso que tiene que ver con una decisión. Como te decía, vivía en Austria y escribía en alemán y tomé la decisión de escribir en castellano, así que tuve que hacer una especie de pequeño aprendizaje.

MS: Además de traductor, eres ensayista y narrador. ¿Esta faceta es consecuencia de la traducción o viceversa? ¿Son actividades que nacieron a la par?

AK: Siempre he escrito. Desde los 17 años. Empecé escribiendo en alemán, para mí. Hay un montón de escritos, papeles míos que tengo por ahí escritos en alemán, no publicados. Digamos que hay una relación permanente con la literatura. La traducción fue otra forma de relacionarme con la literatura. Eso es lo que yo quería: vivir en y para la literatura. La traducción fue una de las formas. La otra es la escritura. Tuve que hacer un proceso que tiene que ver con una decisión. Como te decía, vivía en Austria y escribía en alemán y tomé la decisión de escribir en castellano, así que tuve que hacer una especie de pequeño aprendizaje. Y es que, al principio, no era "lo natural" para mí escribir en castellano. Sin embargo, a través de la traducción, creo que, eso sí, adquiríla destreza y también el manejo de la lengua y la capacidad de expresarme a fondo literariamente en una lengua.

MS: ¿Dirías que, por medio de la traducción, se puede descubrir las posibilidades expresivas de la lengua castellana?

AK: Absolutamente. La traducción es un gran aprendizaje. Curiosamente, ya que comen- zamos hablando de la relación conflictiva con mi padre, él me alababa mucho la traducción como una forma para adquirir soltura en el manejo literario de una lengua. Mi padre se dedicaba a otras cosas, pero también escribía y siempre alababa, siempre decía que una de las formas de entrar en la literatura es la traducción. Lo había olvidado, es curioso, lo olvidé por completo y acabé haciendo eso.

MS: ¿ Has escrito acerca de tu concepción sobre la traducción?

AK: En la revista El Trujamán de la página web del Instituto Cervantes. Todos los días se publica un texto de dos páginas. Desde hace varios años colaboro con ellos. Son textos muy diversos: reflexiones sobre la traducción, alguna anécdota, algún relato breve; es decir, son múltiples formas, aunque todas relacionadas con el tema de la traducción. Si te interesa mi concepción de lo que es la traducción, ahí está plasmada. LPyH

Mario Salvatierra (Mérida, 1988) es escritor y traductor, licenciado en Lengua y Literatura Hispánicas (Uv) y maestro en Traducción por El Colegio de México. Obtuvo el Premio Internacional Ciudad de Mérida 2014 por el poemario Roldán (Ayuntamiento de Mérida/Libros del Marqués, 2015). 